\title{
Nonlinear Stability Analysis of a Composite Girder Cable-Stayed Bridge with Three Pylons during Construction
}

\author{
Xiaoguang Deng and Muyu Liu \\ Hubei Key Laboratory of Roadway Bridge \& Structure Engineering, Wuhan University of Technology, Wuhan 430070, China \\ Correspondence should be addressed to Muyu Liu; liumuyu@whut.edu.cn
}

Received 1 August 2014; Accepted 8 August 2014

Academic Editor: Zhiqiang $\mathrm{Hu}$

Copyright (C) 2015 X. Deng and M. Liu. This is an open access article distributed under the Creative Commons Attribution License, which permits unrestricted use, distribution, and reproduction in any medium, provided the original work is properly cited.

\begin{abstract}
Based on the nonlinear stability analysis method, the 3D nonlinear finite element model of a composite girder cable-stayed bridge with three pylons is established to research the effect of factors including geometric nonlinearity, material nonlinearity, static wind load, and unbalanced construction load on the structural stability during construction. Besides, the structural nonlinear stability in different construction schemes and the determination of temporary pier position are also studied. The nonlinear stability safety factors are calculated to demonstrate the rationality and safety of construction schemes. The results show that the nonlinear stability safety factors of this bridge during construction meet the design requirement and the minimum value occurs in the maximum double cantilever stage. Besides, the nonlinear stability of the structure in the side of edge-pylon meets the design requirement in the two construction schemes. Furthermore, the temporary pier can improve the structure stability, effectively, and the actual position is reasonable. In addition, the local buckling of steel girder occurs earlier than overall instability under load in some cable tension stages. Finally, static wind load and the unbalanced construction load should be considered in the stability analysis for the adverse impact.
\end{abstract}

\section{Introduction}

Due to advanced manufacturing technology and efficient utilization of structural materials, cable-stayed bridge has been demonstrated as an economical solution for long-span bridges and widely applied in recent decades [1]. Since cables instead of interval piers support cable-stayed bridges, they are much more flexible than conventional continuous bridges [2]. The axial forces arising from cable tension make the pylons and girders to be compression-flexure members [3]. When the span length increases, the structural stability problem of cable-stayed bridge is more prominent.

Studies on the stability of cable-stayed bridges have been carried out by many researchers. Shu and Wang investigated the stability characteristics of box-girder cable-stayed bridges by three-dimensional finite element methods taking into account geometric nonlinearity and many design parameters, such as the main span length, the cable arrangement, and the type of pylons [4]. Yoo et al. proposed a modified eigenvalue analysis by introducing the concept of a fictitious axial force to obtain buckling lengths of steel girder members in cable-stayed bridges, which could avoid the problem of generating excessively large buckling lengths in some girder members having small axial forces [5]. Thai and Kim proposed a fiber hinge beam-column model to predict ultimate load-carrying capacity and ultimate behavior of cablestayed bridges, which included both geometric and material nonlinearities [6]. Xi et al. adopted an energy method of analysis for the in-plane ultimate load capacity of cable-stayed bridges with different deck and pylon connection patterns [7]. Although a number of researchers have investigated this issue from different perspectives and some important findings are generalized, almost all of them focus on the stability problem of cable-stayed bridge in completion stage. Actually, the structure of cable-stayed bridge should undergo several system conversions and sustain changing construction loads during the cantilever construction stage. With the increase of the cantilever length, geometric nonlinearity and material nonlinearity will cause secondary internal force and reduce structure stiffness, which make the structural deformation 
and internal force increase. As a result, the structural stability problem of cable-stayed bridge during construction is more important and more complex.

This paper takes Wuhan Erqi Yangtze River Bridge as background, which adopts the structural style of double cable plane composite girder cable-stayed bridge with three pylons. Cantilever splicing construction method is used to erect composite girder, and the maximum cantilever length reaches $308 \mathrm{~m}$, the largest span in the same type of bridges in the world. By using corotational formulation incremental method, to analyze beam-column effect and large displacement effect, ideal elastic-plastic model, and broken-line model, to analyze the material nonlinearity of steel and concrete, respectively, the structural nonlinear stability of this bridge during construction has been researched based on the nonlinear stability analysis method.

\section{Nonlinear Stability Analysis Method}

2.1. Geometric Nonlinearity Analysis Method. Geometric nonlinearity of cable-stayed bridge includes sag effect of stay cable, beam-column effect, and large displacement effect [8].

The cables are assumed to be perfectly flexible and to resist the tensile force only. Under the action of its own dead load and axial tensile force, the deformation of a stay cable consists of two parts, namely, the sag and elastic deformation. The tension stiffness of the table, which varies depending on the sag, is modeled by using an equivalent straight truss element with an equivalent modulus of elasticity. This concept was first proposed by Ernst [9]. The equivalent cable modulus of elasticity can be given as

$$
E_{\text {ep }}=\frac{E_{e}}{1+\left(A(q l \cos \alpha)^{2} / 12 T^{3}\right) E_{e}},
$$

where $E_{\mathrm{ep}}$ is the equivalent modulus of cable, $E_{e}$ is the Young's modulus of cable, $l \cos \alpha$ is the horizontal projected length of the cable, $q$ is the cable weight per unite length of cable, $A$ is the cross-sectional area of cable, and $T$ is the cable tension.

Corotational formulation which developed in recent years can separate the rigid motion of the unit from the deformation under load by building corotational coordinate system which can move with the deformation of the structure and then the rigid motion can be deducted exactly in the incremental formulation, which makes the internal force calculation more accurate [10]. Thus, it can be used to analyze the beam-column effect and large displacement effect accurately.

In Figure 1, $X-Y$ is the main coordinate system, where node coordinate, node displacement, and corner increment are built; $X^{\prime}-Y^{\prime}$ is a corotational coordinate system, where the element displacement $\{\delta\}$ can be denoted as $\left[\begin{array}{llllll}0 & 0 & \theta_{i}^{\prime} & u_{i}^{\prime} & 0 & \theta_{j}^{\prime}\end{array}\right]^{T}$.

In $t_{2}$ moment, the included angle between corotational coordinate system and $X$-axis in main coordinate system is as follows:

$$
\alpha=\arctan \left(\frac{v_{i}-v_{j}+L_{0} \sin \alpha_{0}}{u_{i}-u_{j}+L_{0} \cos \alpha_{0}}\right) .
$$

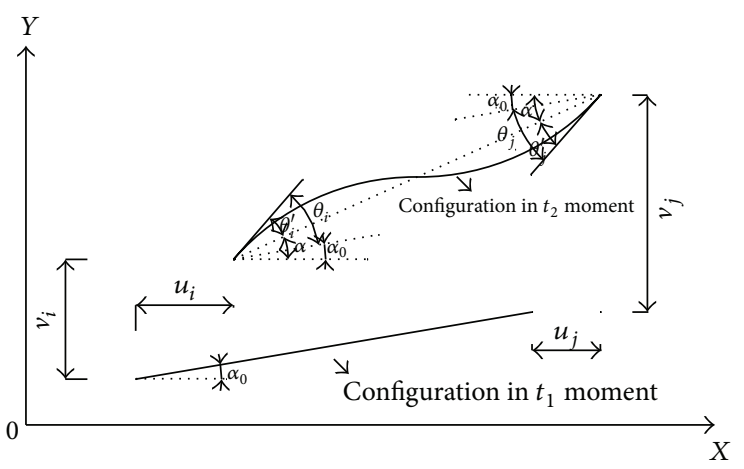

FIGURE 1: Corotational coordinate system.

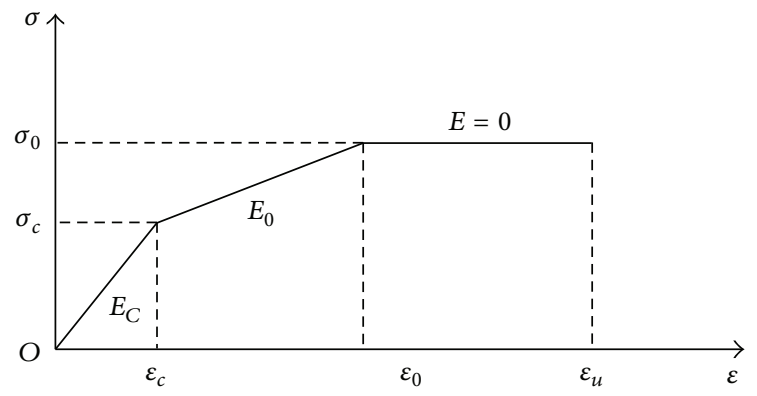

FIGURE 2: Stress-strain curve of concrete.

The rigid motion of the unit $\beta$ is as follows:

$$
\beta=\alpha-\alpha_{0}
$$

So the degrees of freedom of plane beam element decrease to 3 , and the relationship with main coordinate system is as follows:

$$
\begin{gathered}
\theta_{i}^{\prime}=\theta_{i}-\beta, \\
\theta_{j}^{\prime}=\theta_{j}-\beta, \\
u_{j}^{\prime}=S-S_{0}, \\
S \approx \sqrt{\left(v_{i}-v_{j}+L_{0} \sin \alpha_{0}\right)^{2}+\left(u_{i}-u_{j}+L_{0} \cos \alpha_{0}\right)^{2}},
\end{gathered}
$$

where $S_{0}$ and $S$ are arc length of element before and after deformation, respectively.

2.2. Material Nonlinearity Analysis Method. The relationship between stress and strain of concrete and steel is nonlinear. As shown in Figures 2 and 3, the material nonlinearity of steel and concrete are analyzed by ideal elastic-plastic model and broken-line model, respectively.

For Wuhan Erqi Yangtze River Bridge, in the stress-strain curve of deck lab concrete, $\sigma_{0}$ is $38.5 \mathrm{MPa}$ and $\sigma_{c}=14.4 \mathrm{MPa}$, $E_{c}=36 \mathrm{GPa}, \varepsilon_{u}=0.0033, \varepsilon_{0}=0.002, \varepsilon_{c}=0.0004$, and $E_{0}$ $=15.0625 \mathrm{GPa}$. In the stress-strain curve of pylons, $\sigma_{0}=$ $32.4 \mathrm{MPa}, \sigma_{c}=13.8 \mathrm{MPa}, E_{c}=34.5 \mathrm{GPa}, \varepsilon_{u}=0.0033, \varepsilon_{0}=$ $0.002, \varepsilon_{c}=0.0004$, and $E_{0}=11.625 \mathrm{GPa}$. In the stress-strain curve of steel girder, $\sigma_{s}=370 \mathrm{MPa}$ and $E_{g}=210 \mathrm{GPa}$. 


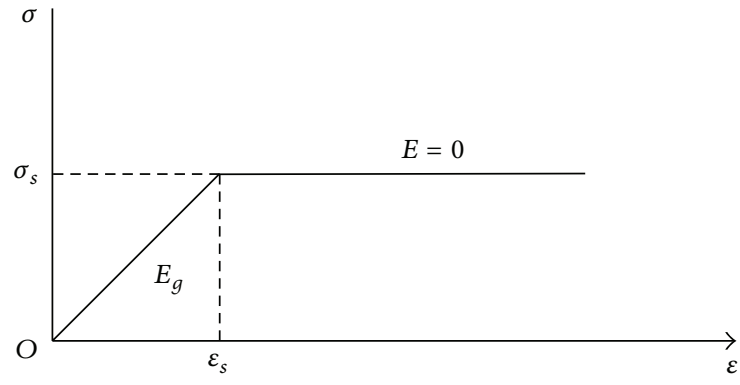

FigurE 3: Stress-strain curve of steel.

2.3. Stability Analysis Method. The essence of Second-order stability of point type is to obtain the structural ultimate load by solving the load-displacement curve based on nonlinear theory.

Considering geometric nonlinearity and material nonlinearity, the basic equation of nonlinear stability is given as

$$
\left(K_{0}+K_{\sigma}+K_{l}\right)\{\delta\}=\{P\},
$$

where $K_{0}$ is the small displacement elastoplastic stiffness matrix, $K_{\sigma}$ is geometric stiffness matrix, and $K_{l}$ is large displacement elastoplastic stiffness matrix.

When the structure integral rigidity matrix $K_{t}\left(K_{t}=\right.$ $\left.K_{0}+K_{\sigma}+K_{l}\right)$ is not positive definite, the cable-stayed bridge reaches the instability ultimate state.

The stability safety factor $\lambda$ during construction process is defined as

$$
\lambda=\frac{P_{c r}}{P_{t}},
$$

where $P_{t}$ is load base during construction process, which includes dead load, construction load, and so forth. $P_{c r}$ is the ultimate bearing capacity, which can be obtained by increasing the load until the structure integral rigidity matrix $\left|K_{t}\right|=0$.

\section{Calculation FEM Model}

3.1. Engineering Situation. Wuhan Erqi Yangtze River Bridge, whose layout is shown in Figure 4, adopts the structural style of double cable plane composite girder cable-stayed bridge with three pylons. The span consists of $90+160+616+$ $616+160+90 \mathrm{~m}$, and the main span is $616 \mathrm{~m}$, which is the largest span bridge of the same type in the world. The I crosssection of steel girder has two longitudinal stiffeners arranged at the lateral part of web and the thickness of the concrete bridge deck is $26 \mathrm{~cm}$. Shear studs are used to connect them and the standard cross-section of composite girder is shown in Figure 5.

There are two construction schemes applied on the structure in the side of edge-pylon. Scheme (1): steel-pipe support method is adopted on the construction of $160 \mathrm{~m}$ composite girder; then, the crane is used to erect the $308 \mathrm{~m}$ composite girder in single cantilever until midspan closure, as shown in Figure 6(a). Scheme (2): the cranes are used to erect the composite girder in double cantilever at the beginning, when the $160 \mathrm{~m}$ composite girder is erected and the side-span closure is done and the crane is used only in one direction until midspan closure, as shown in Figure 6(b).

The cranes are used to erect the composite girder in double cantilever during the construction of the structure in the side of midpylon and a temporary pier is set $204 \mathrm{~m}$ away from the $4 \#$ bridge piers, which will be dismantled after closure, as shown in Figure 7.

3.2. Finite Element Model. The 3D nonlinear finite element model of this bridge during construction is established by MIDAS program, with 3366 elements (3102 beam elements and 264 cable elements). The material parameters in this model are presented in Table 1, and the finite element model is presented in Figure 8.

3.3. Construction Process Stimulation. On the basis of the actual construction process, 127 construction stages are built, containing the construction of the pylons, cyclic splicing of the girder, side-span closure, midspan closure, system transformation, and secondary dead load. Forward-analysis is carried out by activation and passivation function. Typical construction stage is displayed in Figure 9.

\section{Results and Analysis}

4.1. Influence of Geometrical Nonlinearity on Structural Stability. By adopting equivalent modulus method to analyze stay cable sag effect and corotational formulation incremental method to analyze beam-column effect and large displacement effect, the geometrical nonlinear stability of this bridge during construction is researched. Comparisons are presented between results from linear and nonlinear analysis.

Computational vertical load includes dead load and crane load. Moreover, it increases by the same proportion at the same location in calculation.

As shown in Figures 10 and 11, the change between the geometrical nonlinear stability safety factor of structure and the linear elastic stability safety factor is similar, but the former observably reduces the stability safety factor of structure. When considering geometrical nonlinearity, the stability safety factor of the structure in the side of midpylon in the max double cantilever stage drops from 13.88 to 7.48 by $46.1 \%$. And that of the structure in the side of edge-pylon in the max single cantilever stage drops from 13.48 to 8.16 by $39.5 \%$.

As can be seen in Figures 12 and 13, for the structure in the side of edge-pylon and middle-pylon, along with the construction process, the buckling mode turns from the longitudinal instability of pylon to combined instability of pylon and main girder. tural Stability. The geometrical nonlinear stability safety 


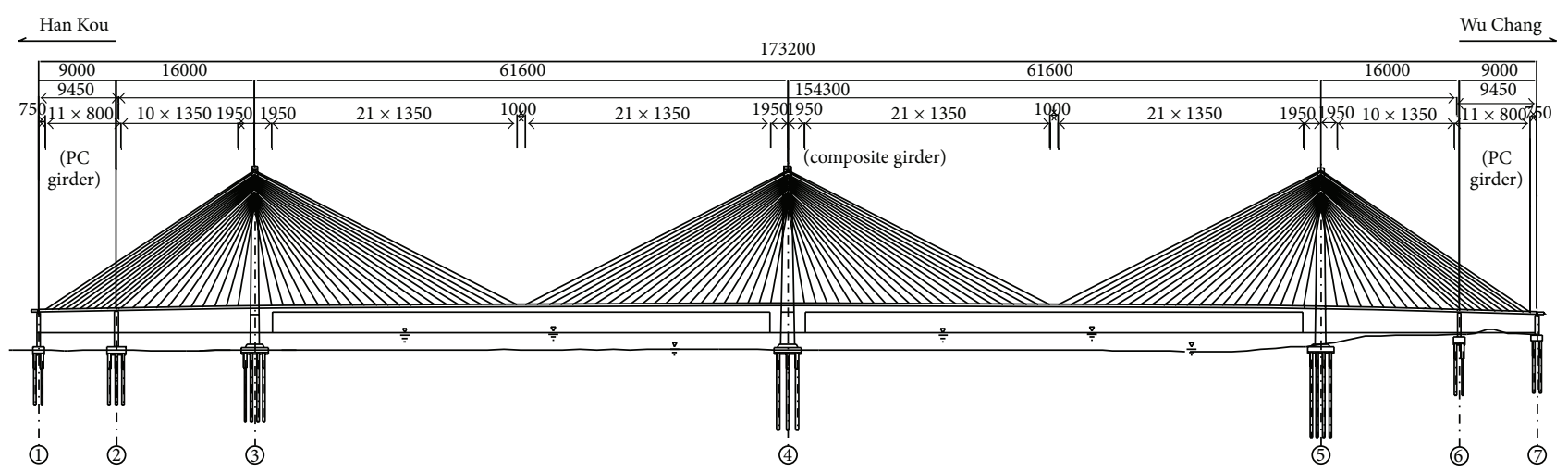

FIgure 4: Bridge layout of Wuhan Erqi Yangtze River Bridge.

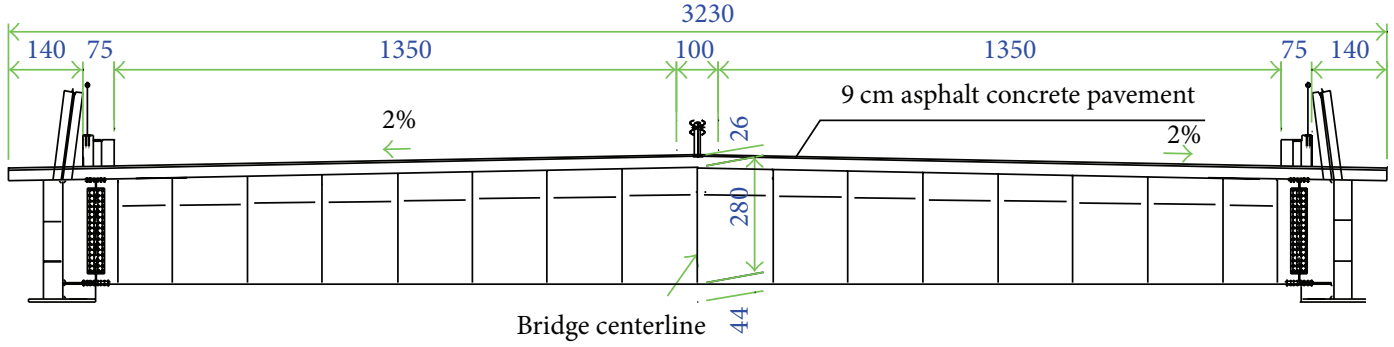

FiguRE 5: Standard cross-section of composite girder.

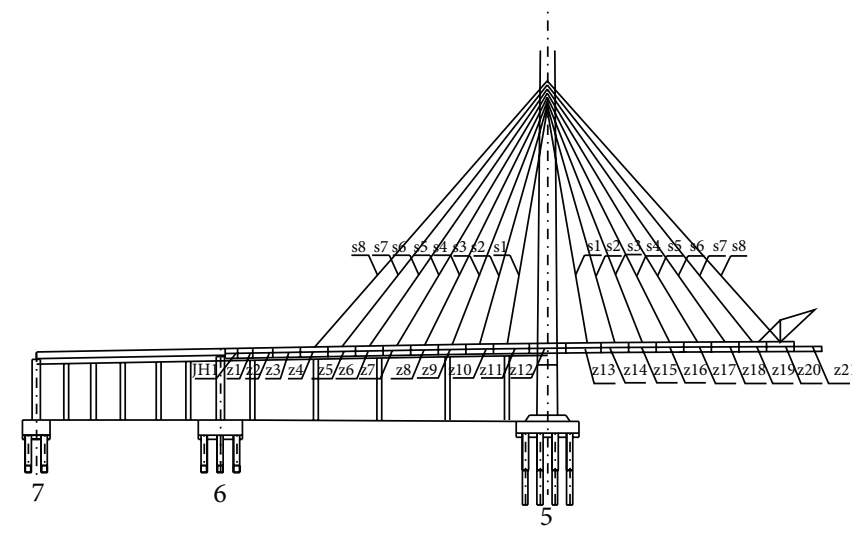

(a) Construction scheme (1)

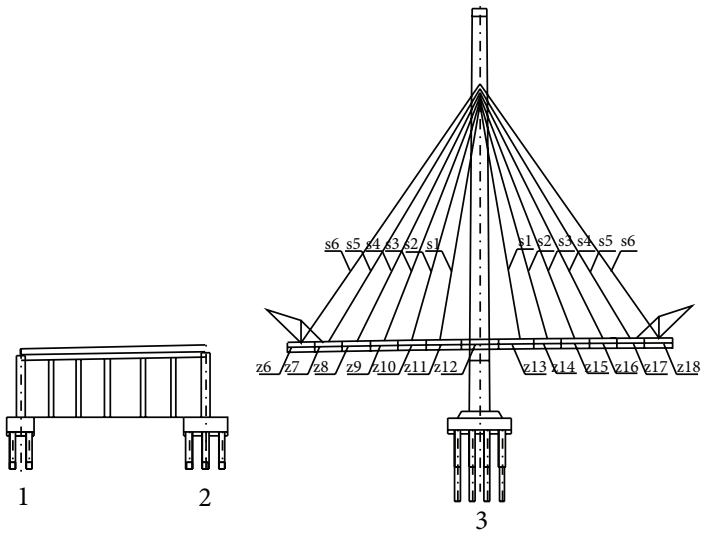

(b) Construction scheme (2)

FIGURE 6: Construction schemes applied on the structure in the side of edge-pylon.

TABLE 1: Each material parameter of structure in model.

\begin{tabular}{lccc}
\hline Structure & Material & Modulus of elasticity $(\mathrm{MPa})$ & Density $\left(\mathrm{kN} / \mathrm{m}^{3}\right)$ \\
\hline Steel girder & Q370qD & $2.06 \times 10^{5}$ & 76.98 \\
Pylon & C50 & $3.45 \times 10^{4}$ & 26 \\
Bridge deck, PC beam & C60 & $3.6 \times 10^{4}$ & 26 \\
Stay cable & PE galvanized steels trend & $1.95 \times 10^{5}$ & 78.5 \\
\hline
\end{tabular}




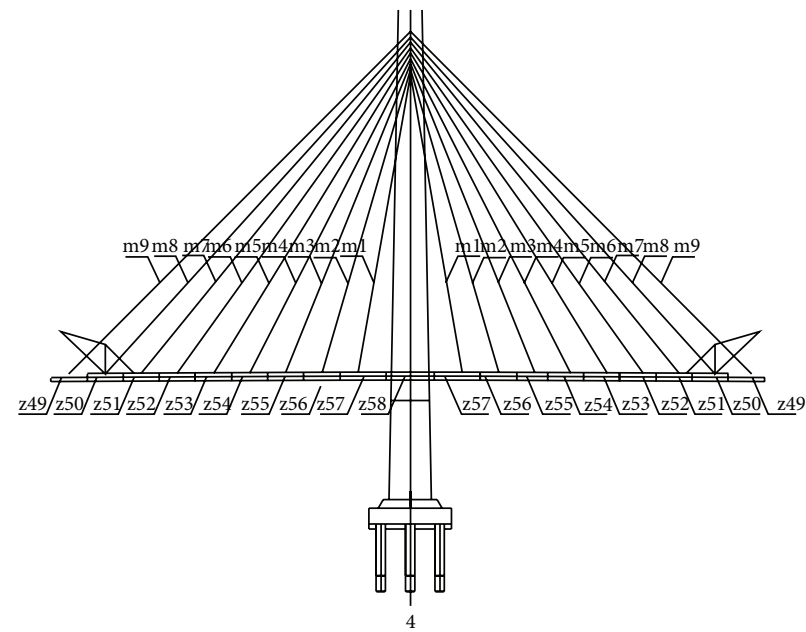

(a) Double cantilever construction scheme

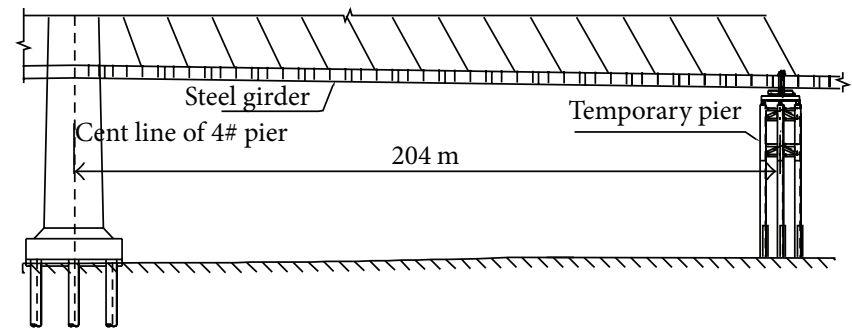

(b) The set of location of temporary pier

Figure 7: Construction scheme applied on the structure in the side of midpylon.

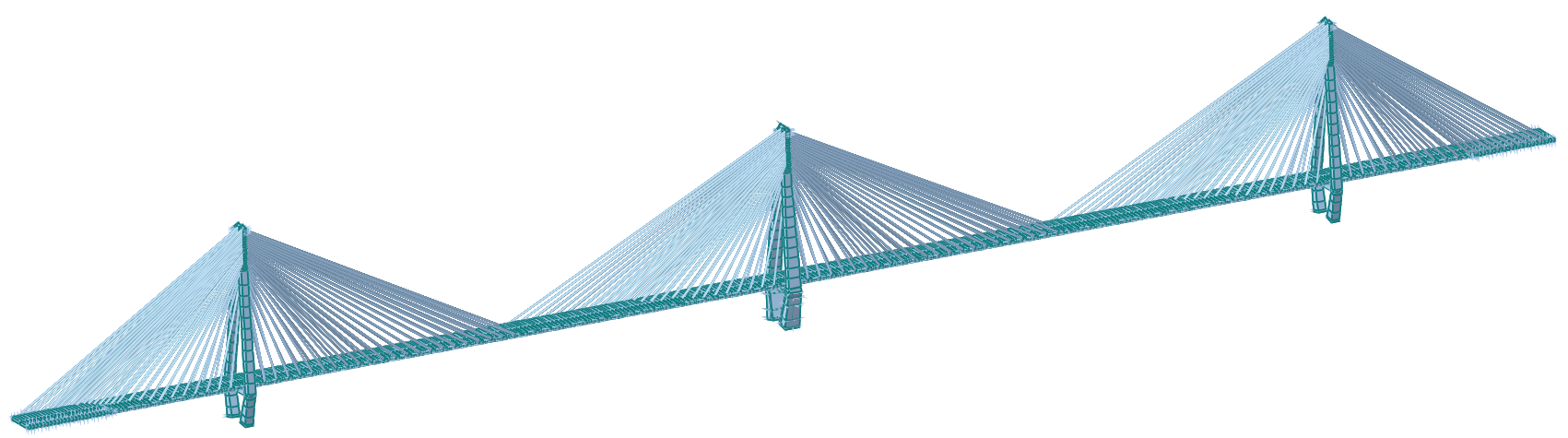

Figure 8: Global finite element model.

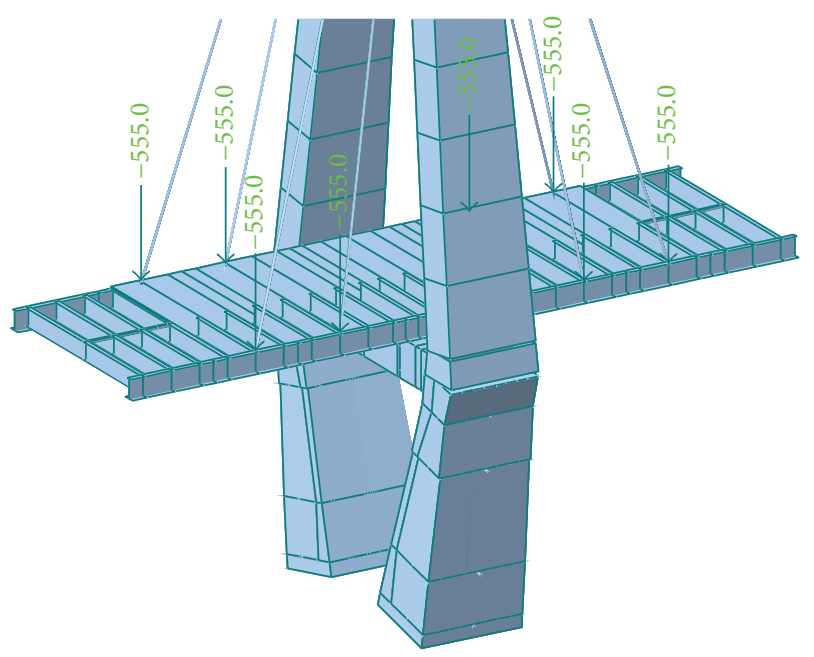

(a) Hoist steel girder

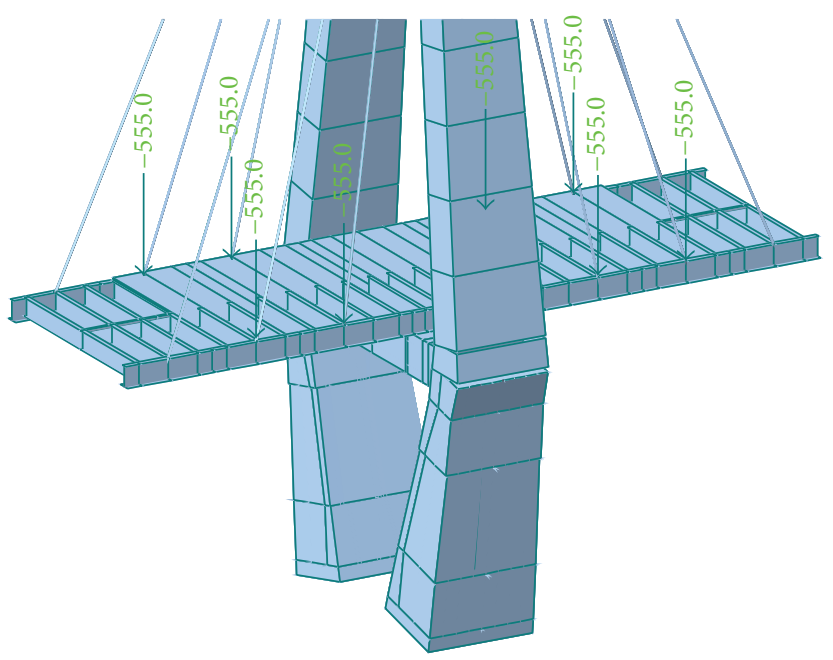

(b) First tension of cable

Figure 9: Typical construction stage. 
Mathematical Problems in Engineering

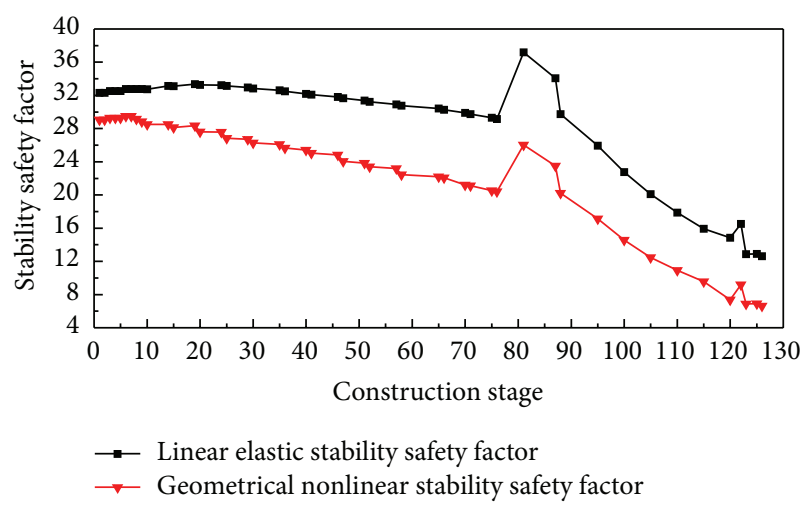

FIGURE 10: Stability safety factors of the structure in the side of midpylon.

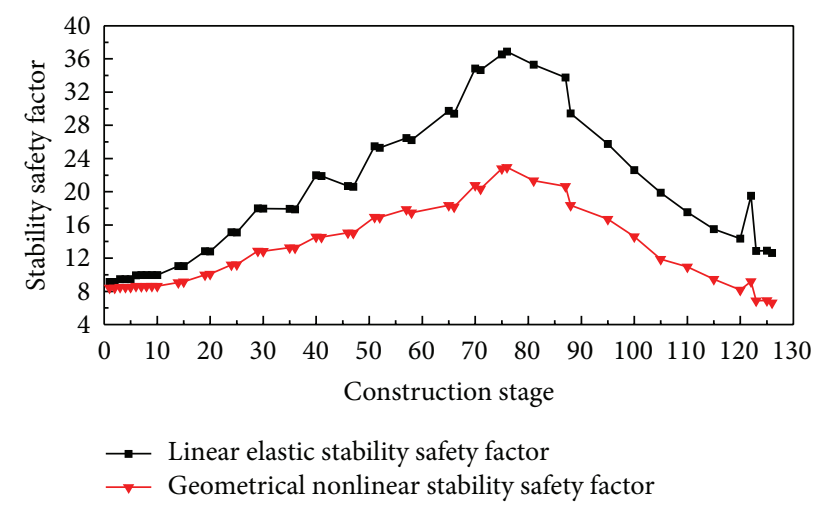

FIGURE 11: Stability safety factors of the structure in the side of edgepylon in Scheme (1).

factors of structure in the side of edge-pylon in the two schemes are given in Figure 14.

Scheme (1). Because the closure construction of side span has occurred, cable-stayed tensioning enhances the elastic support of the main pylon. However, the flexibility of the main girder structure increases rapidly along with the cantilever construction, and when it comes to a certain degree, vertical instability of the main girder happens, so the geometrical nonlinear stability safety factor of structure in the side of edge-pylon increases firstly and then decreases. The lowest geometrical nonlinear stability safety factor happens in the maximum double cantilever stage of 8.16 , which meets the design requirement for being over 4 .

Scheme (2). In the beginning of symmetrical cantilever splicing construction, the longitudinal instability of pylon happens firstly, and the geometrical nonlinear stability safety factor of structure in the side of edge-pylon changes smoothly until the closure construction of side span, which provides an elastic support for the main pylon equally and increases the geometrical nonlinear stability safety factor of structure from 7.36 to 14.46. After the closure construction of side span, the
TABLE 2: Influence of construction load on the structural stability.

\begin{tabular}{lccc}
\hline Structure & $\begin{array}{c}\text { Dead load } \\
\text { only }\end{array}$ & $\begin{array}{c}\text { Both dead load } \\
\text { and crane load }\end{array}$ & Diff \\
\hline $\begin{array}{l}\text { Structure in the side of } \\
\text { midpylon }\end{array}$ & 8.38 & 7.48 & $10.7 \%$ \\
$\begin{array}{l}\text { Structure in the side of } \\
\text { edge-pylon }\end{array}$ & 8.86 & 8.16 & $7.9 \%$ \\
\hline
\end{tabular}

change is the same as Scheme (1). So the geometrical nonlinear stability safety factor of structure in the side of edgepylon changes smoothly at first and then increased suddenly, followed by a decrease. The structural stability in both the construction schemes meets the stability requirement.

4.3. Influence of Temporary Pier on Structural Stability. The structure in the side of midpylon adopts symmetric cantilever construction technology, and the unilateral maximum cantilever length reaches $304.5 \mathrm{~m}$. Between the $3 \#$ bridge pier and $4 \#$ bridge pier, there is a temporary pier $204 \mathrm{~m}$ away from the $4 \#$ bridge piers. Geometrical nonlinear stability analysis of the structure with the presence or absence of a temporary pier is researched, respectively, to get the influence of a temporary pier on the structural stability.

Computational vertical load includes dead load and crane load. Moreover, it increases by the same proportion at the same location in calculation. The geometrical nonlinear stability safety factors of structure in both situations are shown in Figure 15.

It can be indicated from the stability safety factor curve without temporary pier that the geometrical nonlinear stability safety factors of structure begin to decrease further when the construction goes to ZL56 segment (almost $200 \mathrm{~m}$ away from the $4 \#$ bridge piers). However, the geometrical nonlinear stability safety factors of structure increase from 20.04 to 26.15 when a temporary bridge pier is set at this place to provide the vertical and lateral constraints to the main girder, enhance the structure stiffness, and reduce the cantilever end deformation of the main girder. Therefore, it is reasonable to set temporary pier at the location which is $204 \mathrm{~m}$ away from $4 \#$ bridge piers when considering the stability.

4.4. Influence of Construction Load on Structural Stability. The main construction load is 22 ton crane load. The structure in the side of midpylon adopts symmetric cantilever construction technology and that of edge-pylon adopts single cantilever construction technology, which makes construction load unbalanced.

For researching the influence of construction load on the structural stability, the calculation is divided into two situations: considering dead load only; considering both dead load and crane load. Load increases by the same proportion at the same location in calculation.

As shown in Table 2, crane load makes the geometrical nonlinear stability safety factors of structure in the side of midpylon decrease from 8.38 to 7.48 by $10.7 \%$ and that of 


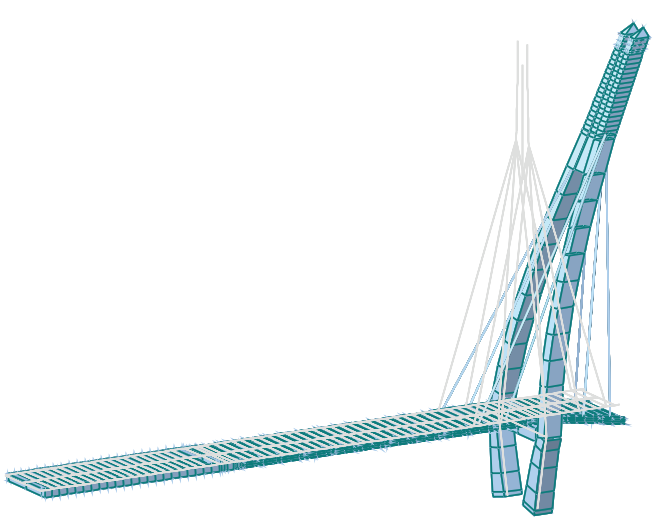

(a)

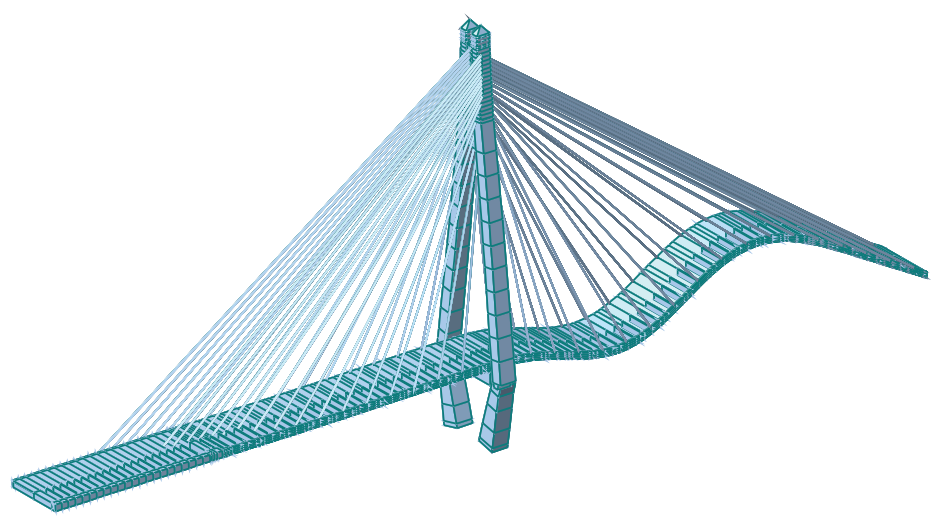

(b)

FIGURE 12: Buckling mode of structure in the side of edge-pylon in Scheme (1).

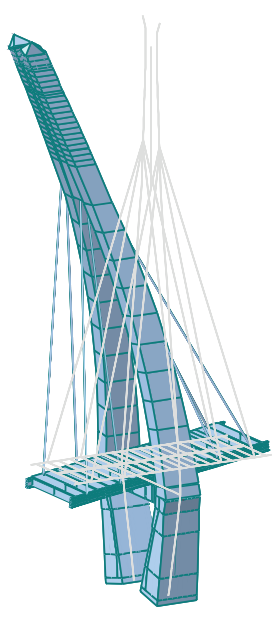

(a)

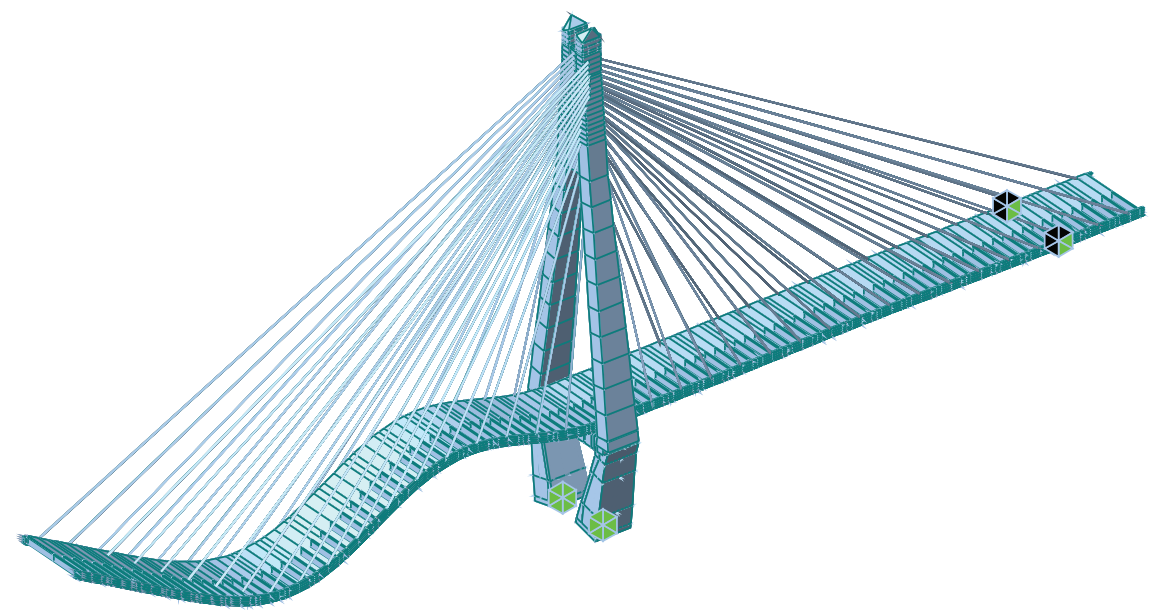

(b)

FIGURE 13: Buckling mode of structure in the side of middle-pylon.

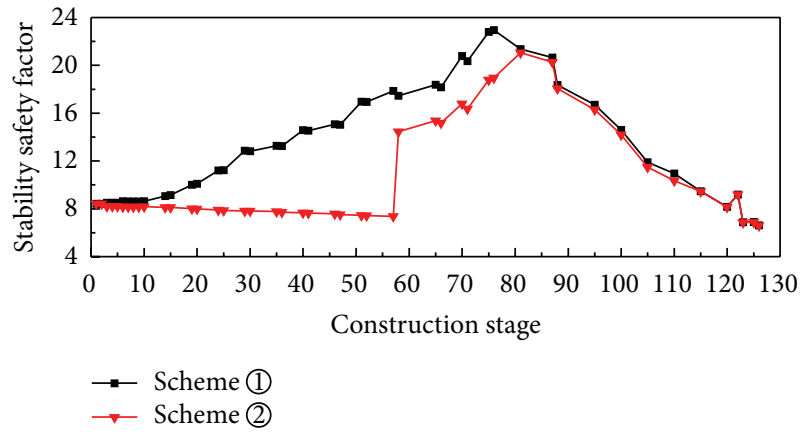

FIGURE 14: Geometrical nonlinear stability safety factors of structure in the two schemes.

structure in the side of edge-pylon decrease from 8.86 to 8.16 by $7.9 \%$.

4.5. Influence of Wind Load on Structural Stability. This bridge is easily affected by wind load because it stretches

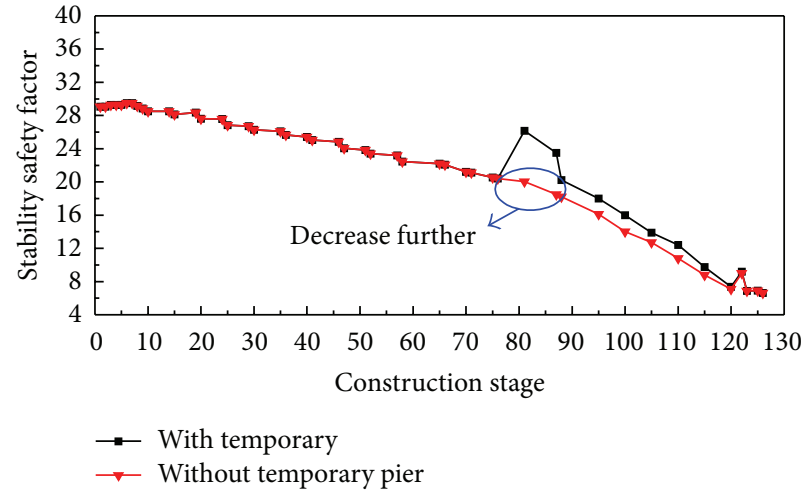

FIGURE 15: Geometrical nonlinear stability safety factors of structure in the side of middle-pylon.

across Yangtze River. So it is important to research the influence of wind load on the structural stability during construction. The three direction component forces of wind 
TABLE 3: Three direction component forces of wind load in the max double cantilever stage.

\begin{tabular}{lccc}
\hline Wind attack angle & Drag factor $C_{H}$ & Lift factor $C_{V}$ & Lifting moment factor $C_{M}$ \\
\hline$-3^{\circ}$ & 1.3910 & -0.2680 & 0.0177 \\
$0^{\circ}$ & 1.2680 & -0.0640 & 0.0430 \\
$3^{\circ}$ & 1.5420 & 0.3160 & 0.0512 \\
\hline
\end{tabular}

TABLE 4: Computational formula of the three direction component forces of wind load.

\begin{tabular}{llrr}
\hline Three direction component forces & Lateral wind load & Vertical wind load & Twisting moment \\
\hline Computational formula & $F_{H}=\frac{1}{2} \rho V_{g}^{2} C_{H} H$ & $F_{V}=\frac{1}{2} \rho V_{g}^{2} C_{v} B$ & $M=\frac{1}{2} \rho V_{g}^{2} C_{M} B^{2}$ \\
\hline
\end{tabular}

TABLE 5: Influence of wind load on geometrical nonlinear stability safety factor.

\begin{tabular}{lcccc}
\hline Structure & Dead load only & \multicolumn{4}{c}{ Wind attack angle } \\
& $-3^{\circ}$ & $0^{\circ}$ & $3^{\circ}$ \\
\hline $\begin{array}{l}\text { Structure in the side of } \\
\text { midpylon }\end{array}$ & 8.38 & 7.73 & 8.16 & 8.60 \\
$\begin{array}{l}\text { Structure in the side of } \\
\text { edge-pylon }\end{array}$ & 8.86 & 8.23 & 8.47 & 8.93 \\
\hline
\end{tabular}

load in the max double cantilever stage are obtained by wind tunnel testing [11].

The three direction component forces of wind load, which act on unit length of main girder, are shown in Table 4, where $\rho$ is sir density with the value of $1.25 \mathrm{~kg} / \mathrm{m}^{3}$; in this paper, $V_{g}$ is static gust speed with the value of $38.7 \mathrm{~m} / \mathrm{s}, H$ is projection height of main girder with the value of $4.5 \mathrm{~m}$, and $B$ is projection width of main girder with the value of $31.5 \mathrm{~m}$. $C_{H}, C_{V}$, and $C_{M}$ are drag factor, lift factor, and lifting moment factor, whose values can be obtained from Table 3 .

As shown in Table 5, the influence is greatest when the wind attack angle is $-3^{\circ}$. The geometrical nonlinear stability safety factor of structure in the side of midpylon drops from 8.38 to 7.73 by $7.8 \%$ and that of structure in the side of edgepylon drops from 8.86 to 8.23 by $7.1 \%$. Actually, when the wind attack angle is $-3^{\circ}$, the wind load provides lateral wind load and vertical wind load, which intensifies the vertical instability of main girder for the same direction with dead load.

4.6. Influence of Local Buckling on Structural Stability. Computational vertical load includes dead load and crane load. Moreover, it increases by the same proportion at the same location in calculation.

In some stages of cable tension, the local buckling of steel girder occurs earlier than overall instability, as shown in Figure 16.

For example, in the stage of the 13th cable tension, the geometrical nonlinear stability safety factors of structure in view of local buckling is 15.52 , while the value is 20.56 for overall instability. Actually, when the cable is tensioned, steel girder in both sides should undertake a large lateral bending moment, but the lateral bending rigidity of I-steel is small. In addition, the bridge deck is not concreted, which can provide
TABLE 6: The stability safety factors of structure with or without material nonlinearity.

\begin{tabular}{lccc}
\hline Construction stage & $\begin{array}{c}\text { Without material } \\
\text { nonlinearity }\end{array}$ & $\begin{array}{c}\text { With material } \\
\text { nonlinearity }\end{array}$ & Diff \\
\hline $\begin{array}{l}\text { Max double cantilever } \\
\text { stage }\end{array}$ & 6.82 & 2.18 & $68.0 \%$ \\
$\begin{array}{l}\text { Max single cantilever } \\
\text { stage }\end{array}$ & 7.59 & 2.21 & $70.1 \%$ \\
\hline
\end{tabular}

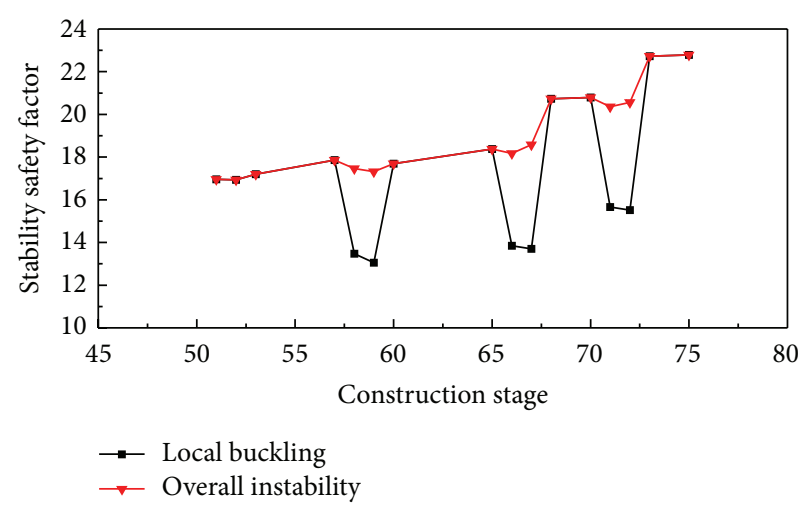

FIGURE 16: Geometrical nonlinear stability safety factors of structure in view of local buckling.

lateral restraint; in consequence, the local buckling of steel girder occurs earlier than overall instability under load.

4.7. Influence of Material Nonlinearity on Structural Stability. The mode of this bridge in max cantilever stage is built by ANSYS program, where the nonlinear parameters of stressstrain curve of bridge deck C60, pylon C50, and steel girder Q370qD are imported into it.

For researching the influence of construction load on the stability, the calculation is divided into two situations; all the above-mentioned factors are considered with or without material nonlinearity. The stability safety factors of structure are obtained by analyzing the load-displacement curve of pylon and main girder.

As shown in Table 6, material nonlinearity has a great influence on structural stability. When the stress of main girder researches to a certain degree, the elasticity modulus will be 0 . The nonlinear stability safety factor of structure in 
the side of midpylon in consideration of material nonlinearity is 2.18 , larger than 1.75 , which meets the design requirement.

\section{Conclusions}

Nonlinear structural stability analysis of Wuhan Erqi Yangtze River Bridge during construction has been carried out in this paper, and the conclusions are organized as follows.

(1) The lowest nonlinear structural stability safety factor of structure occurs in the max double cantilever stage with the value of 2.18 , larger than 1.75 , which meets the design requirement. Along with the construction, the geometrical nonlinear stability safety factors of structure in the side of midpylon drops from 29.07 to 7.38 and that of structure in the side of edgepylon increases from 8.41 to 22.95 and then drops to 8.16. The diminishing rate becomes large when the cantilever length increases.

(2) Both the two construction schemes meet the stability requirement, and the location of temporary pier is 204 maway from $4 \#$ bridge piers, which is reasonable for increasing the geometrical nonlinear stability safety factors of structure from 20.04 to 26.15.

(3) The local buckling of steel girder occurs earlier than overall instability under load in the cable tension stage due to the smaller lateral bending rigidity of I-steel, and the lack of lateral restraint provided by bridge deck.

(4) Static wind load and the unbalanced construction load should be considered in the stability analysis for the adverse impact.

(5) The main girder construction period of Wuhan Erqi Yangtze River Bridge was from January, 2011, to September, 2011. The actual structure state matched well with theory state during the whole construction. The structural stability can be guaranteed in each construction stage for the construction scheme is reasonable.

\section{Conflict of Interests}

The authors declare that there is no conflict of interests regarding the publication of the paper.

\section{Acknowledgments}

The research described in this paper was financially supported by the National Natural Science Fund, "Stability of High Web in Long-span Steel-concrete Composite Bridge Based on the Elastic Rotational Restraint Boundary" (no. 51378405) and the Natural Science Fund of Hubei province (no. 2013CFA049). These supports are gratefully acknowledged.

\section{References}

[1] R. Karoumi, "Some modeling aspects in the nonlinear finite element analysis of cable supported bridges," Computers \& Structures, vol. 71, no. 4, pp. 397-412, 1999.

[2] Y.-C. Wang, "Number of cable effects on buckling analysis of cable-stayed bridges," Journal of Bridge Engineering, vol. 4, no. 4, pp. 242-248, 1999.

[3] D.-H. Choi, H. Yoo, J.-H. Koh, and K. Nogami, "Stability evaluation of steel cable-stayed bridges by elastic and inelastic buckling analyses," International Journal of Structural Stability and Dynamics, vol. 7, no. 4, pp. 669-691, 2007.

[4] H.-S. Shu and Y.-C. Wang, "Stability analysis of box-girder cable-stayed bridges," Journal of Bridge Engineering, vol. 6, no. 1, pp. 63-68, 2001.

[5] H. Yoo, H.-S. Na, E.-S. Choi, and D.-H. Choi, "Stability evaluation of steel girder members in long-span cable-stayed bridges by member-based stability concept," International Journal of Steel Structures, vol. 10, no. 4, pp. 395-410, 2010.

[6] H.-T. Thai and S.-E. Kim, "Second-order inelastic analysis of cable-stayed bridges," Finite Elements in Analysis and Design, vol. 53, pp. 48-55, 2012.

[7] Z. Xi, Y. Xi, and H. Xiong, "Ultimate load capacity of cablestayed bridges with different deck and pylon connections," Journal of Bridge Engineering, vol. 19, no. 1, pp. 15-33, 2014.

[8] P.-H. Wang, H.-T. Lin, and T.-Y. Tang, "Study on nonlinear analysis of a highly redundant cable-stayed bridge," Computers and Structures, vol. 80, no. 2, pp. 165-182, 2002.

[9] H. J. Ernst, "Der E-modul von seilen unter Beruecksichtigung des durchhanges," Der Bauingenieur, vol. 40, no. 2, pp. 52-55, 1965.

[10] J. M. Pajot and K. Maute, "Analytical sensitivity analysis of geometrically nonlinear structures based on the co-rotational finite element method," Finite Elements in Analysis and Design, vol. 42, no. 10, pp. 900-913, 2006.

[11] L. Yuan, Y. Yongxin, G. Zengwei, and M. Ting Ting, "Nonlinear wind-induced static instability analysis for long-span cablestayed bridges with three towers and two main spans," Structural Engineers, vol. 28, no. 1, pp. 87-93, 2012. 


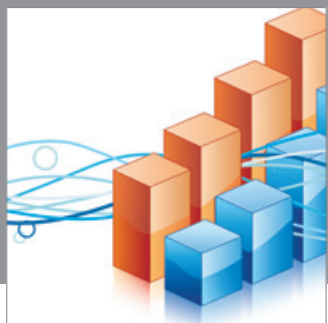

Advances in

Operations Research

mansans

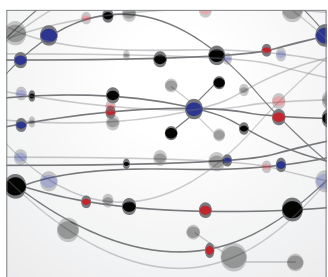

The Scientific World Journal
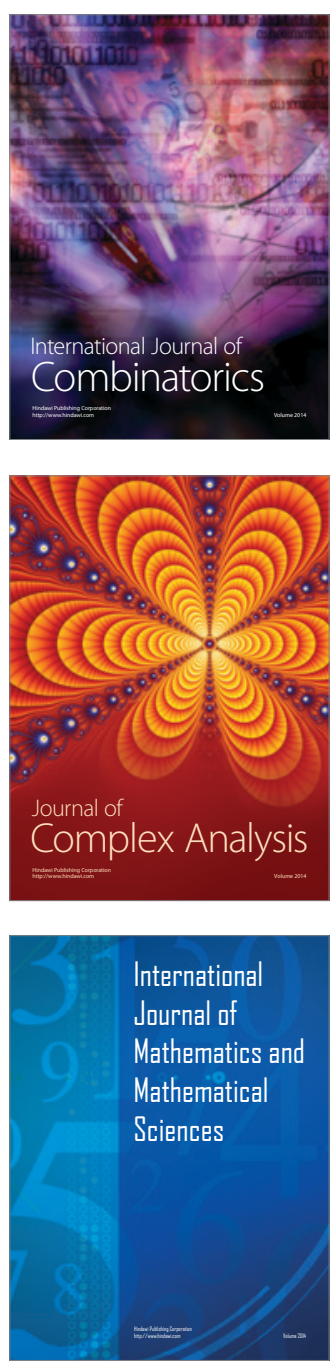
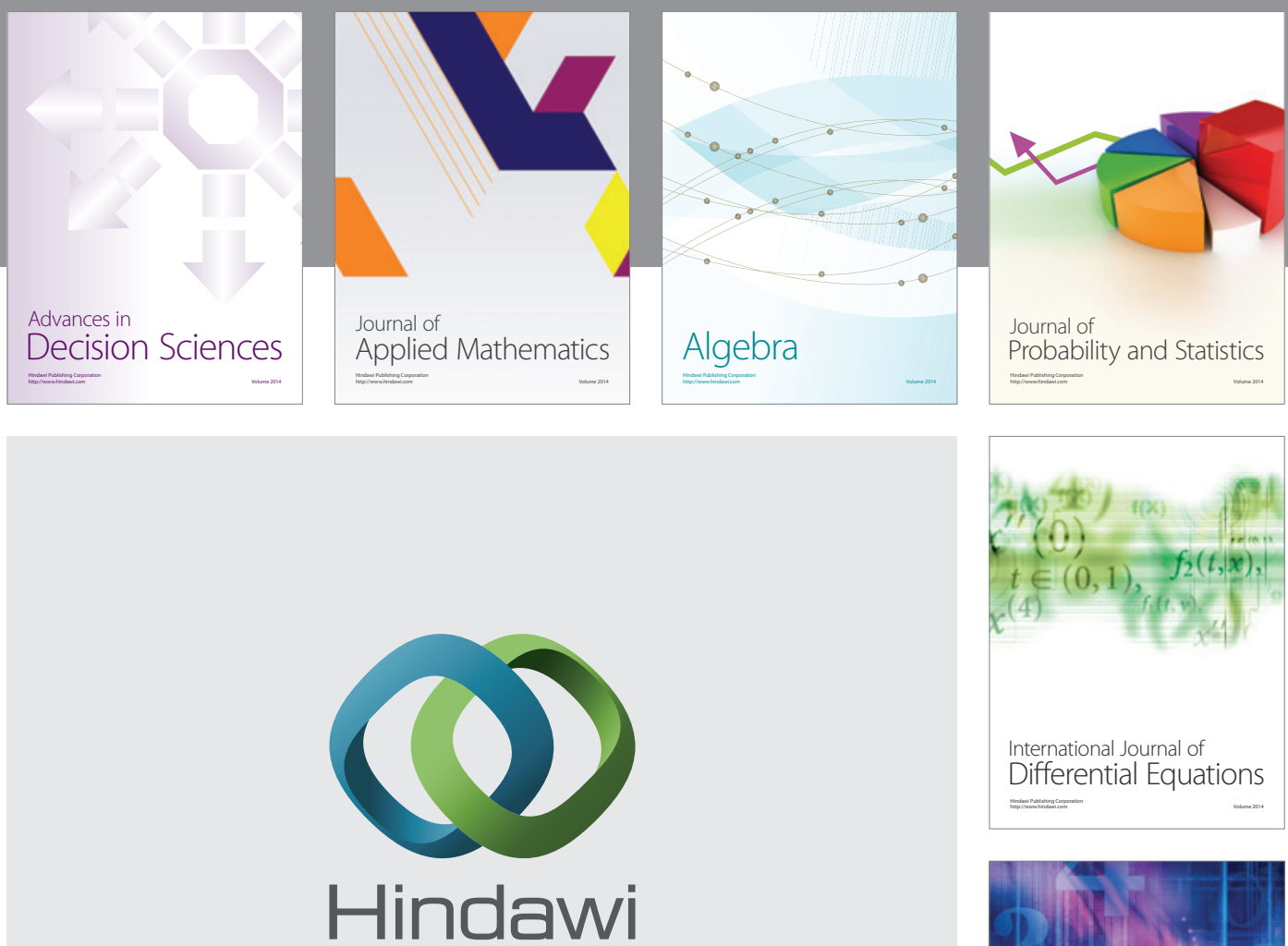

Submit your manuscripts at http://www.hindawi.com
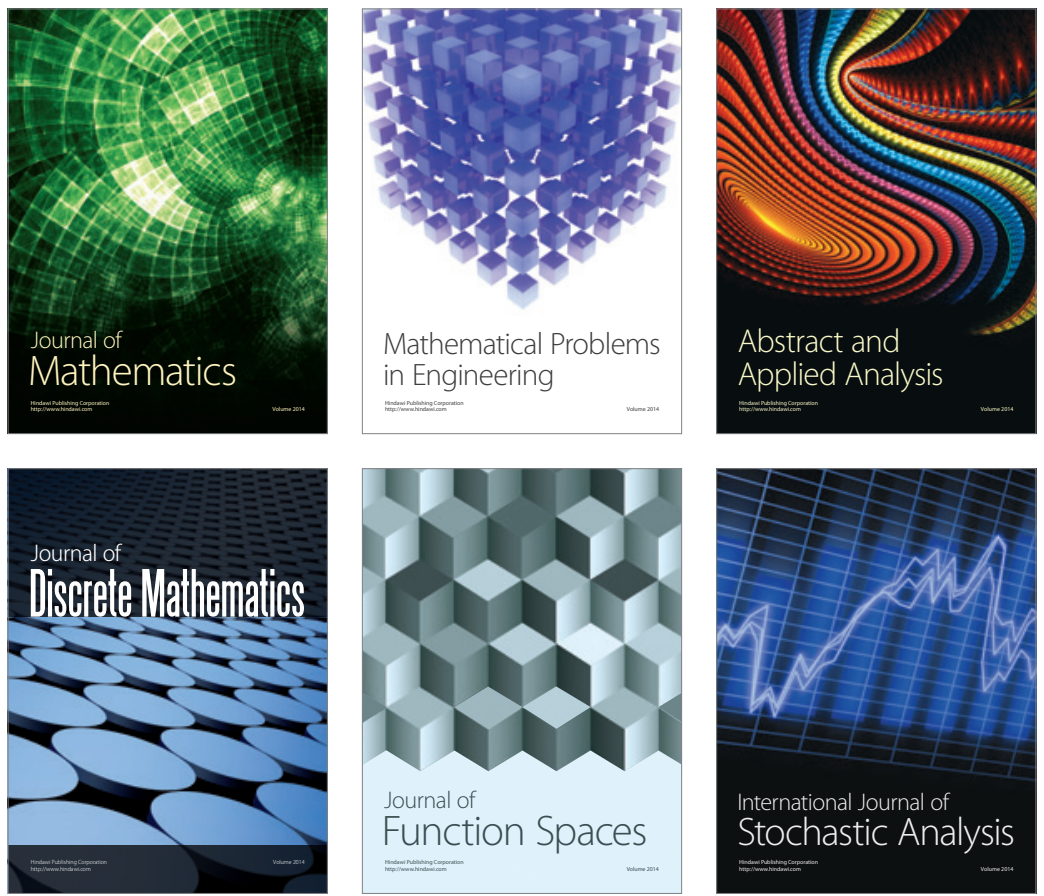

Journal of

Function Spaces

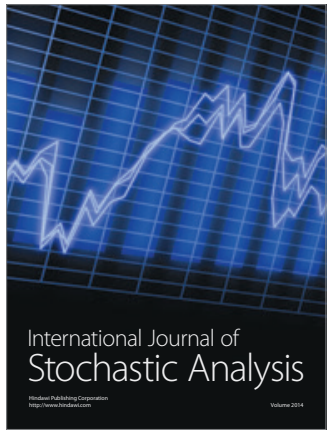

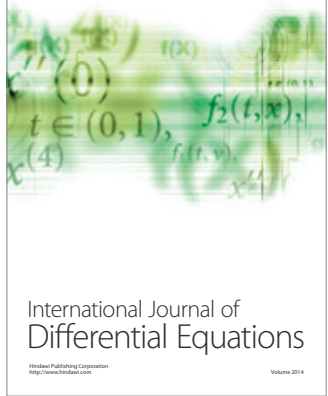
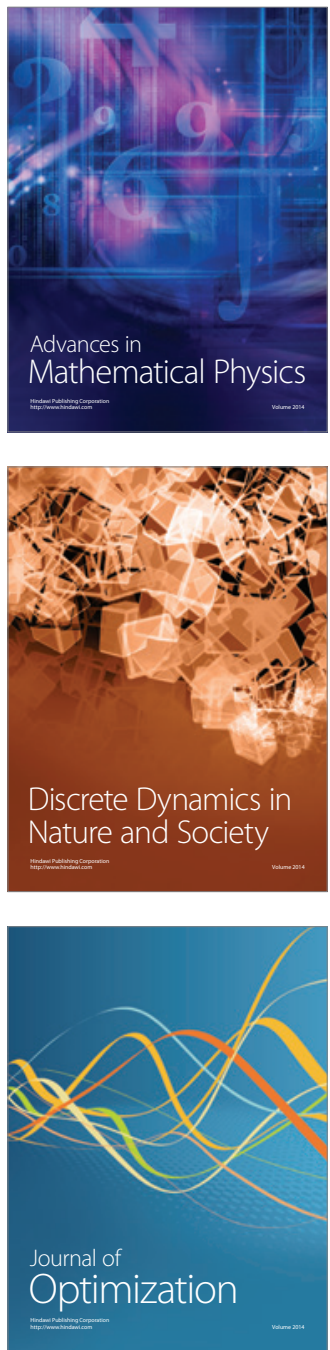